\title{
Increased frequency of asymptomatic bronchial hyperresponsiveness in nonasthmatic patients with food allergy
}

\author{
A. Thaminy*, C. Lamblin*,+, T. Perez*, C. Bergoin*, A.B. Tonnel*,+, B. Wallaert*,+
}

Increased frequency of asymptomatic bronchial hyperresponsiveness in nonasthmatic patients with food allergy. A. Thaminy, C. Lamblin, T. Perez, C. Bergoin, A.B. Tonnel, B. Wallaert. (C) ERS Journals Ltd 2000.

ABSTRACT: Subclinical inflammation in gut mucosa has been demonstrated in bronchial asthma suggesting the whole mucosal system is involved in allergic diseases. The presence of subclinical bronchial involvement was assessed by nonspecific bronchial hyperresponsiveness (BHR) in nonasthmatic patients with food allergy (FA).

BHR was studied in 35 patients with various manifestations of FA without foodinduced asthma. Sixteen had a previous history of asthma and/or rhinitis to aeroallergens (group A), whereas 19 patients (group B) did not. BHR was defined by a provocative dose causing a $20 \%$ fall in forced expiratory volume in one second of (PC20) $<8 \mathrm{mg} \cdot \mathrm{mL}^{-1}$ of methacholine.

Asymptomatic BHR occurred frequently in nonasthmatic patients with FA (10 of $19,53 \%$ ); this did not significantly differ from patients with FA and a previous history of asthma and/or rhinitis to aeroallergens (13 of $16,81 \%)$. PC20 was significantly lower in group $A\left(1.84 \pm 0.53 \mathrm{mg} \cdot \mathrm{mL}^{-1}\right)$ than in group $B\left(3.35 \pm 0.74 \mathrm{mg} \cdot \mathrm{mL}^{-1} ; \mathbf{p}<0.05\right)$. The number of patients with positive skin tests to aeroallergens was similar between groups. Sequential evaluation, performed 1 year after initial evaluation, in 7 nonasthmatic patients (group B) demonstrated a similar level of BHR.

The present study demonstrated that BHR is a frequent finding in nonasthmatic patients with food allergy which may be due, at least in part, to a subclinical inflammatory process in the bronchi.

Eur Respir J 2000; 16: 1091-1094.

Subclinical inflammatory changes in gut mucosa have been recently demonstrated in patients with asthma, suggesting that a diffuse involvement of the mucosal immune system occurs as a cause or as a consequence in asthma [1]. Conversely several clinical studies demonstrated that inflammatory diseases of gut mucosa, were associated with subclinical involvement of bronchial mucosa [2-4]. For example, an increased frequency of asymptomatic bronchial hyperresponsiveness (BHR) was reported in nonasthmatic patients with inflammatory bowel disease. This finding suggests that the inflammatory bowel disease alone favours the development of nonspecific BHR, probably through the activation of the common mucosal immune system [4].

The authors took this into consideration and hypothesized that subclinical BHR may be present in nonasthmatic patients with food allergy (FA). To demonstrate this, they investigated the presence of nonspecific BHR using an inhaled methacholine provocation test in 35 consecutive patients with various manifestations of FA, excluding food-induced asthma.

\section{Patients and methods}

\section{Patients and procedure}

Thirty-five nonsmoking patients with FA but without food-induced asthma or rhinitis (19 females and 16 males; mean age $34 \pm 3$ yrs), were included in the study.
*Clinique des Maladies Respiratoires, Hôpital A. Calmette, Centre Hospitalier Regional et Universitaire Lille, Lille, France. ${ }^{+}$INSERM U416, Institut Pasteur, Boulevard du Professeur Calmette, Cedex, France.

Correspondence: B. Wallaert, Clinique des Maladies Respiratoires, Service de Pneumologie et Immuno-allergologie, Hôpital A. Calmette, 59037 Lille cedex. Fax: 33 320446693.

Keywords: Asthma, bronchial hyperresponsiveness, food allergy, gut mucosa

Received: December 271999

Accepted after revision June 12000

This study was supported by the Institut National de al Santé et de la recherche médicale and Centre Hospitalier de Recherche Clinique de Lille (Programme Hospitalier de Recherche Clinique 971916).
The diagnosis of FA was established using clinical criteria and selected laboratory procedures [5] including: 1) historical documentation of reactions to specific foods; 2) positive skin-prick tests to a specific food allergen and the serum specific immunoglobulin-E (IgE) antibodies directed against the food allergen, measured by the Phadebas radioallergosorbent test (RAST, Pharmacia diagnostic, Upsalla, Sweden); 3) resolution of symptoms under a strict food allergen free diet to observe whether the reported symptoms will be resolved by the removal of one or more foods from the diet; 4) rapid and reproducible clinical symptoms after a single-blind placebo-controlled challenge; and 5) correlation between the positive food allergen ingestion challenge and the results of skin tests and the serum specific IgE antibodies directed against the food allergen. All patients exhibited type 1 hypersensitivity symptoms which occurred minutes or a few hours after ingestion of the food allergen (table 1). The singleblind placebo-controlled challenge was not performed in patients who reported anaphylactic reactions. In these patients, the diagnosis of FA relied on criteria 1-3 only. The single-blind placebo-controlled challenge, with the native food mixed with apple compote, induced the reproducible clinical symptoms within a few minutes. Examination of stools and systematic serological tests, against the standard parasitic diseases, were performed in order to discard the possibility of a parasitic involvement at the small intestine level. A food allergen elimination diet was given after diagnosis, which resulted 
Table 1. - Clinical characteristics of the 35 patients with food allergy

\begin{tabular}{|c|c|c|}
\hline & Group A & Group B \\
\hline Subjects $n$ & 16 & 19 \\
\hline Age yrs & $34 \pm 4$ & $34 \pm 3$ \\
\hline Urticaria & 12 & 14 \\
\hline Angiooedema & 13 & 15 \\
\hline Anaphylactic shock & 4 & 6 \\
\hline Digestive symptoms & 2 & 6 \\
\hline Positive skin tests to aeroallergens & 12 & 8 \\
\hline House dust mite & $10 *$ & 5 \\
\hline Animal danders & 0 & 0 \\
\hline Pollens & 8 & 7 \\
\hline Moulds & 0 & 0 \\
\hline Eosinophils cells $\cdot \mathrm{mm}^{-3}$ & $258 \pm 36$ & $453 \pm 171$ \\
\hline Total IgE kU. $\mathrm{L}^{-1}$ & $444 \pm 144$ & $433 \pm 177$ \\
\hline \multicolumn{3}{|l|}{ Food hypersensitivity } \\
\hline Drupaceous/umbelliferous ${ }^{\#}$ & 5 & 9 \\
\hline Exotic fruits $^{+}$ & 6 & 9 \\
\hline Solanaceous & 3 & 7 \\
\hline Peanut & 4 & 3 \\
\hline Crustaceans & 6 & 2 \\
\hline
\end{tabular}

Results are presented as mean \pm SEM. $*$ : significantly different from group $\mathrm{B}, \mathrm{p}<0.05$; " : group includes, peach, strawberry, carrot, celery; ${ }^{+}$: group includes, kiwi, banana, avocado; ${ }^{\star}$ : group includes, tomato, sweet pepper. Group A: patients with a previous history of asthma and/or rhinitis; Group B: patients without a history of asthma and/or rhinitis; IgE: immunoglobulin E.

in resolution of the symptoms for all patients. All the patients were untreated at the time of the study.

Respiratory evaluation included skin-prick tests to aeroallergens, spirometric measurements and methacholine challenge. Respiratory evaluation was performed at least 2 months after diagnosis of FA and the last manifestations of FA. Skin-prick test to aeroallergens (house dust mite, animal danders, pollens, moulds) were performed in all cases. Asthma was defined according to the criteria suggested by the American Thoracic Society (ATS) [6]. Exclusion criteria for patients with a previous history of asthma were a forced expiratory volume in one second (FEV1) $<70 \%$ predicted (pred) value, lower respiratory tract infection in the previous 8 weeks, asthmatic exacerbation in the preceding 8 weeks and treatment with inhaled or oral corticosteroids in the 4 months before the study. Rhinitis was defined as a characteristic history of perennial or seasonal nasal symptoms (sneezing, rhinorrhoea, obstruction, anosmia and itching). Overall, 16 patients (group A) had a previous history of asthmatic reactions and/or rhinitis due to hypersensitivity to aeroallergens and 19 patients did not exhibit any symptoms (group B).

\section{Methods}

Skin-prick tests. Skin-prick tests were performed as recommended [7]. Positive controls were histamine $(10 \mathrm{mg}$. $\mathrm{mL}^{-1}$ ) and codeine phosphate. The negative control solution was the diluent used to preserve the allergen extracts. Wheal diameters with these preparations ranged 3-7 $\mathrm{mm}$. Skin tests were read at the peak of their reaction by measuring the wheel and the flare $15 \mathrm{~min}$ after the performance of the tests. Skin tests giving a wheal diameter $>3 \mathrm{~mm}$ when compared with the negative control were considered to be positive.

Food challenge. Food challenge was performed using apple compote as the vehicle. The vehicle itself was used as a placebo and the patients were given a volume that was approximately the same as that containing the challenge. The $\beta$-agonists, theophylline and cromolyn were avoided for $48 \mathrm{~h}$ prior to the challenge. An initial dose of $10-500 \mathrm{mg}$ of dried food was administered in the vehicle. Increments progressed by doubling for several steps. Sequential evaluation of pulmonary function was performed during the food challenge (every 15 min during the first hour and then every hour) and no significant changes in FEV1 were demonstrated. If no reaction was seen during the observation period, the challenge was judged as being negative $[8,9]$.

Pulmonary function tests and methacholine challenge. All measurements were made in the sitting position. FEV1, forced vital capacity (FVC) and maximal forced mid-expiratory flow (FEF25\%-75\%) were obtained from flow/volume curves using a spirometer (Medgraphics, St Paul, MN, USA). The largest values obtained for FVC, FEV1 and FEF25\%-75\% from the first three technically satisfactory forced expirations were selected. All data were expressed in absolute values and in per cent of predicted normal values (\% pred) [10].

Methacholine challenge was performed sequentially with a DeVilbiss 646 nebulizer (output of $0.13 \mathrm{~mL} \cdot \mathrm{min}^{-1}$ ) [10]. Patients inhaled the diluent solution for $2 \mathrm{~min}$ of tidal breathing followed by doubling concentrations of methacholine at intervals of $5 \mathrm{~min}$, ranging $0.125-8$ $\mathrm{mg} \cdot \mathrm{mL}^{-1}$. The end-point for the procedure was a $20 \%$ fall in FEV1 from post diluent values or when a methacholine concentration of $8 \mathrm{mg} \cdot \mathrm{mL}^{-1}$ was obtained. The lowest, technically satisfactory FEV1 value obtained between $90 \mathrm{~s}$ and 3 min was used in the analysis to calculate the doseresponse curve. Dose-response curves were constructed by plotting FEV1 against increasing concentration of methacholine as a log scale. The provocative concentration (PC20) was defined as the methacholine concentration necessary to decrease FEV 1 by $20 \%$ from baseline values. BHR was defined by a $\mathrm{PC}_{20}<8 \mathrm{mg} \cdot \mathrm{mL}^{-1}$. Asymptomatic BHR was defined as a methacholine PC20 $<8 \mathrm{mg} \cdot \mathrm{mL}^{-1}$, in the absence of symptoms suggestive of asthma (intermittent wheeze, chest tightness, dyspnoea, recurrent cough), in subjects who reported never being told by a physician that they had asthma or that they required any asthma medication.

\section{Statistical analysis}

Group data are expressed as mean \pm standard error (SEM). Statistical analysis was performed using the MannWhitney U-test for quantitative data. Differences in qualitative data among the groups were examined by Fisher's exact test. Differences between paired data were investigated using the Wilcoxon's signed-rank test. A pvalue $<0.05$ was considered to be statistically significant.

\section{Results}

The clinical characteristics of the group A (previous history of asthma or rhinitis) and group B patients (without 
previous history of asthma or rhinitis) are reported in table 1. There was no significant difference for age, clinical manifestations of FA, prevalence of positive skin tests to aeroallergens and IgE levels between the two groups. Blood eosinophil count tended to be higher in group B than in group $\mathrm{A}$.

There was no significant difference in baseline FEV1 $(\mathrm{mL})$ between the two groups although there was a trend toward a lower FEV1 (\%) in group A (table 2). The prevalence of BHR did not significantly differ in the two groups. Thirteen of 16 patients in group A (81\%) and ten of 19 in group B $(53 \%)$ exhibited nonspecific BHR. Methacholine sensitivity was higher in group A than in group $\mathrm{B}$. Mean $\mathrm{PC} 20$ was significantly lower in group A $\left(1.84 \pm 0.53 \mathrm{mg} \cdot \mathrm{mL}^{-1}\right.$ methacholine) than in group $\mathrm{B}$ $(3.35 \pm 0.74 ; \mathrm{p}<0.05)$. In addition, FEV1 decrease was higher in group A than in group B at $0.125 \mathrm{mg} \cdot \mathrm{mL}^{-1}$ and at $0.5 \mathrm{mg} \cdot \mathrm{mL}^{-1}$ of methacholine concentrations (table 1 , $\mathrm{p}<0.05)$. Clinical and functional characteristics of the patients did not differ according to the presence of BHR.

Clinical and functional characteristics were similar in patients with or without positive skin tests to aeroallergens. The prevalence of nonspecific BHR was not statistically different between patients with positive skin tests to allergens (13 of 20) (65\%) and patients with negative skin tests to aeroallergens (10 of 15$)(66.6 \%)$. In addition, mean $\mathrm{PC} 20$ was similar in these 2 groups $\left(2.6 \pm 0.6 \mathrm{mg} \cdot \mathrm{mL}^{-1}\right.$ methacholine and $2.3 \pm 0.7 \mathrm{mg} \cdot \mathrm{mL}^{-1}$ methacholine, respectively). Among the group B patients, the prevalence of positive skin tests to aeroallergens was similar in patients with BHR ( 4 of 10) and in patients without BHR (4 of 9).

Sequential evaluation was performed $1 \mathrm{yr}$ after initial evaluation in seven patients from group B (three patients with positive skin tests to aeroallergens). These patients remained free of respiratory symptoms and did not exhibit any symptoms of FA between the two evaluations. PC20 remained stable between the two evaluations $(3.15 \pm 0.7$ $\mathrm{mg} \cdot \mathrm{mL}^{-1}$ at the first evaluation, $2.9 \pm 0.6 \mathrm{mg} \cdot \mathrm{mL}^{-1}$ at the second evaluation).

Table 2. - Functional characteristics of the 35 patients with food allergy

\begin{tabular}{lcc}
\hline & Group A & Group B \\
\hline Subjects n & 16 & 19 \\
FEV1 mL & $3176 \pm 214$ & $3055 \pm 158$ \\
FEV1 \% & $95.2 \pm 3$ & $101.1 \pm 2.4$ \\
FVC mL & $3832 \pm 228$ & $3617 \pm 186$ \\
FVC \% & $100.6 \pm 2.8$ & $102 \pm 2.8$ \\
FEV $1 / \mathrm{FVC} \%$ & $83.2 \pm 1.7$ & $86.4 \pm 1.4$ \\
Normal response to methacholine & 3 & 9 \\
BHR & 13 & 10 \\
PC20 mg.mL $\mathrm{mL}^{-1}$ & $1.84 \pm 0.53 *$ & $3.35 \pm 0.74$ \\
Fall in FEV1 & & \\
$0.125 \mathrm{mg} \cdot \mathrm{mL}^{-1} *$ & $5.44 \pm 1.43 *$ & $1.21 \pm 0.41$ \\
$0.5 \mathrm{mg} \cdot \mathrm{mL}^{-1}$ & $12.1 \pm 3.33^{*}$ & $3.39 \pm 1.12$ \\
\hline
\end{tabular}

Results are presented as mean \pm SEM. *: expressed as the percentage of forced expiratory volume in one second (FEV1) decrease after the indicated concentration of methacholine. FVC: forced vital capacity; BHR: bronchial hyperresponsiveness; PC20: provocative methacholine concentration causing a $20 \%$ fall in FEV1; Group A: patients with previous history of asthma and/or rhinitis; Group B: patients without history of asthma and/or rhinitis.

\section{Discussion}

The present study clearly demonstrated an increased prevalence of asymptomatic BHR in nonasthmatic patients with FA $(53 \%)$, which appeared to be similar to that observed in patients with FA and a previous history of asthma or allergic rhinitis $(81 \%)$. In addition, it was found that asymptomatic BHR persisted over one year in nonasthmatic patients with FA, despite food allergen avoidance over the same period. To the best of the authors knowledge, this is the first demonstration of an increased prevalence of asymptomatic BHR in nonasthmatic patients with FA.

Since the reported prevalence of nonspecific BHR in the general population is low, the findings suggest that FA favours, by itself, the development of nonspecific BHR. The prevalence of nonspecific BHR in healthy subjects has been investigated in several studies [11-14]. The results of these studies have demonstrated that the prevalence of BHR in healthy adult subjects was low and increased with the degree of atopy. The prevalence of BHR, as defined by a histamine $\mathrm{PC}_{20}<8 \mathrm{mg} \cdot \mathrm{mL}^{-1}$, was reported in a random population of 400 subjects by COCKROFT et al. [13]. The author found that the incidence of BHR was $5.9 \%$ in nonatopic nonasthmatic subjects and $9.2 \%$ in atopic nonasthmatic subjects. MALO et al. [14] also reported a low level $(8 \%)$ of nonspecific BHR, as defined by a methacholine $\mathrm{PC} 20<16 \mathrm{mg} \cdot \mathrm{mL}^{-1}$, in 100 healthy subjects. The role of sensitization to aeroallergens, in the development of asymptomatic BHR associated with FA, was examined since previous studies have identified atopy as a risk factor for the development of asymptomatic BHR. The authors found a higher frequency of sensitization to house dust mites in group A than in group B. This finding reflects the fact that dust mites are frequently the cause of asthma or allergic rhinitis. However, the prevalence of nonspecific BHR was similar whether sensitization to aeroallergens existed or not. Furthermore, the prevalence of asymptomatic BHR (group B patients) was similar in patients with positive skin tests to aeroallergens and in patients with negative skin tests to aeroallergens, suggesting that sensitization to aeroallergens is not the sole factor that determines the development of BHR associated with FA.

In FA, the sensitization to allergens occurs at the intestinal level but the clinical manifestations of FA are polymorphic. FA as the cause of asthma or increased nonspecific BHR in asthmatics appears to be infrequent (2-8.5\%) [15-19]. Respiratory symptoms induced by food allergens, such as asthmatic symptoms, are rare. However, previous studies suggest that food-induced allergic reactions may increase airway reactivity in asthmatic patients with moderate-to-severe food-induced asthma [16-19]. In this study, the authors focused on the assessment of nonspecific BHR in nonasthmatic patients with FA after allergen avoidance, in order to investigate the presence of a subclinical bronchial involvement in FA. The fact that nonspecific BHR persisted over $1 \mathrm{yr}$ after allergen avoidance suggests that nonspecific BHR in FA is not due to chronic allergen intake. This finding is in line with a previous report in which inflammatory changes of gut mucosa persisted several months after the last reported symptoms of FA [20]. 
An increased frequency of asymptomatic BHR was previously reported in several diseases of the mucosal immune system: allergic rhinitis, nonallergic rhinitis with eosinophilic syndrome, nasal polyposis and Crohn's disease [4, 21-23]. In these diseases, the presence of asymptomatic BHR was closely associated with bronchial inflammatory cellular changes, suggesting the involvement of the common mucosal immune system. It can be hypothesized that asymptomatic BHR in FA occurs through the recirculation of immune cells, namely T-lymphocytes, via the common mucosal immune system from the intestinal to the bronchial mucosa. Previous studies have examined the interaction between bronchial and intestinal mucosae in humans. The authors previously demonstrated that the intestinal permeability to chromium-51 labelled ethylenediamine tetraacetic acid (CrEDTA) was significantly higher in patients with asthma than in patients with chronic obstructive pulmonary disease or controls [24]. In addition, the intestinal mucosa in asthmatic patients exhibited "airway-like" pathological abnormalities, including a significant accumulation of mononuclear cells, of eosinophils and of inflammatory cells expressing interleukins 3 and 5 and granulocyte-macrophage colony stimulating factor in the lamina propria [1]. These asymptomatic pathological abnormalities of gut mucosa in asthma, were similar to those observed in the bronchial mucosa, supporting the hypothesis that the whole common mucosal immune system is involved as a cause or as a consequence in asthma.

The findings of the present study, which demonstrated an increased prevalence of nonspecific bronchial hyperresponsiveness suggest that subclinical abnormalities of the bronchial mucosa may occur in patients with food allergy. The significance of nonspecific bronchial hyperresponsiveness in food allergy is unclear; whether it predisposes to asthma, or is the expression of the activation of the bronchial mucosal immune system in patients, remains to be determined.

\section{References}

1. Wallaert B, Desreumaux P, Copin MC, et al. Immunoreactivity for interleukin 3 and 5 and granulocyte/ macrophage colony stimulating factor of intestinal mucosa in bronchial asthma. J Exp Med 1995; 182: 1897-1904.

2. Wallaert B, Colombel JF, Tonnel AB, et al. Evidence of lymphocytis alveolitis in Crohn's disease. Chest 1985; 87: 363-367.

3. Adenis A, Colombel JF, Lecouffe P, et al. Increased pulmonary and intestinal permeability in Crohn's disease. Gut 1992; 33: 678-682.

4. Louis E, Louis R, Drion V, et al. Increased frequency of bronchial hyperresponsiveness in patients with inflammatory bowel disease. Allergy 1995; 50: 729-733.

5. Crowe SE, Perdue MH. Gastrointestinal food hypersensitivity: basic mechanisms of pathophysiology. Gastroenterology 1992; 103: 1075-1095.

6. American Thoracic Society. Standards for the diagnosis and care of patients with chronic obstructive pulmonary disease (COPD) and asthma. Am Rev Respir Dis 1987; 136: 225-244.

7. Position paper: Allergen standardization and skin tests. The European Academy of Allergology and Clinical Immunology. Allergy 1993; 48: 48-82.
8. Bernstein IL, Storms WW. Practice, parameters for allergy diagnostic testing. Joint Task Force on Practice Parameters for the Diagnosis and Treatment of Asthma. The American Academy of Allergy, Asthma and Immunology. Ann Allergy Asthma Immunol 1995; 75: 543-625.

9. Bock SA, Sampson HA, Atkins FM, et al. Double blind, placebo-controlled food challenge as an office procedure: a manual. J Allergy Clin Immunol 1988; 82: 986-997.

10. Quanjer PhH, Tammeling GJ, Cotes JE, Pedersen OF, Peslin R, Yernault JC. Lung volumes and forced ventilatory flows. Report working party standardisation of lung function tests. European Community for Steel and Coal. Eur Respir J 1993; 6, (Suppl. 6): 5-40.

11. Annesi I, Oryszczyn MP, Neukirch F, Orvoen-Frija E. Relationship of upper airways disorders to FEV1 and bronchial hyperresponsiveness in an epidemiologiocal study. Eur Respir J 1992; 5: 1104-1110.

12. Sparrow D, O'Connor G, Colton T, Barry CL, Weiss ST. The relationship of non specific bronchial responsiveness to the occurrence of respiratory symptoms and decreased levels of pulmonary function. Am Rev Respir Dis 1987; 135: $1255-1260$.

13. Cockcroft DW, Murdock KY, Berscheid A. Relationship between atopy and bronchial hyperresponsiveness to histamine in a random population. Ann Allergy 1984; 54: 26-29.

14. Malo JL, Pineau L, Cartier A, Martin RR. Reference values of the provocative concentrations of methacholine that cause a $6 \%$ and $20 \%$ changes in forced expiratory volume in one second in a normal population. Am Rev Respir Dis 1983; 128: 8-11.

15. Sampson HA. Food allergy. Part 1: Immunopathogenesis and clinical disorders. J Allergy Clin lmmunol 1999; 103: 717-728.

16. Wilson NM. Bronchial hyperreactivity in food and drink intolerance. Ann Allergy 1988; 61: 75-79.

17. Bock SA. Respiratory reactions induced by food challenges in children with pulmonary disease. Pediatr Allergy Immunol 1992; 3: 188-194.

18. James JM, Bernhisel-Broadbent J, Sampson HA. Respiratory reactions provoked by double-blind food challenges in children. Am J Respir Crit Care Med 1994; 149: 59-64.

19. James JM, Eigenmann PA, Eggleston PA, Sampson HA. Airway reactivity changes in asthmatic patients undergoing blinded food challenges. Am J Respir Crit Care Med 1996; 153: 597-603.

20. Vandezande LM, Wallaert B, Desreumaux $\mathrm{P}$, et al. Interleukin-5 immunoreactivity and mRNA expression in gut mucosa from patients with food allergy. Clin Exp Allergy 1999; 29: 652-659.

21. Foresi A, Leone C, Pelucchi A, et al. Eosinophils, mast cells, and basophils in induced sputum from patients with seasonal allergic rhinitis and perennial asthma: relationship to methacholine responsiveness. J Allergy Clin Immunol 1997; 100: 58-64.

22. Leone C, Teodoro C, Pelucchi A, et al. Bronchial responsiveness and airway inflammation in patients with nonallergic rhinitis with eosinophilia syndrome. J Allergy Clin Immunol 1997; 100: 775-780.

23. Lamblin C, Gosset P, Salez F, et al. Eosinophilic airway inflammation in nasal polyposis. $J$ Allergy Clin Immunol 1999; 103: 85-92.

24. Benard A, Desreumaux P, Huglo D, Hoorelbeke A, Tonnel AB, Wallaert B. Increased intestinal permeability in bronchial asthma. $J$ Allergy Clin Immunol 1996; 97: $1173-1178$. 